\title{
Role of Green Tea in Reducing Epidermal Thickness upon Ultraviolet Light-B Injury in BALB/c Mice
}

\author{
Snur M. A. Hassan, ${ }^{1}$ Adel J. Hussein, ${ }^{2}$ and Azad K. Saeed ${ }^{1}$ \\ ${ }^{1}$ Department of Anatomy and Histopathology, College of Veterinary Medicine, Sulaimani University, Sulaimani 46, Iraq \\ ${ }^{2}$ Department of Anatomy and Histology, College of Veterinary Medicine, Basrah University, Basrah 61, Iraq \\ Correspondence should be addressed to Snur M. A. Hassan; snur.amin@univsul.edu.iq
}

Received 12 July 2015; Revised 3 September 2015; Accepted 7 September 2015

Academic Editor: Qianzheng Zhu

Copyright (C) 2015 Snur M. A. Hassan et al. This is an open access article distributed under the Creative Commons Attribution License, which permits unrestricted use, distribution, and reproduction in any medium, provided the original work is properly cited.

\begin{abstract}
The main environmental source for skin damage is ultraviolet (UV) radiation. Many adverse effects have been recognized as the result of prolonged cutaneous exposure to solar ultraviolet radiation, such as erythema, edema, apoptosis, hyperplastic responses, photo-aging, and skin cancer development. Green tea provides photo-protection against UV radiation through many mechanisms including anti-inflammatory, immunomodulatory, and antioxidant properties. The aim of this study was to evaluate the effect of green tea in reducing epidermal thickness on mouse's skin exposed to UVB irradiation. Thirty mice (Mus musculus species, BALB/c strain) underwent this study and were divided into 3 groups: control group ( $n=10$ mice), without UVB exposure and green tea administration; exposure group $(n=10$ mice), which were exposed to UVB light only; and treatment group $(n=10$ mice), which were exposed to UVB light and treated with $1 \mathrm{~mL}$ of green tea through oral gavage. Mice from both groups (exposure and treatment) were subjected to UVB irradiation 4 days/week (20 minutes/day, 4 weeks). It concluded that oral administration of green tea was provided photo-protection against UVB induced hyperplasia; therefore, it can be regarded as a natural alternative for photo-protection.
\end{abstract}

\section{Introduction}

The skin is comprised of the epidermis and the vascularized dermis. It provides a vital self-protective barrier against environmental insults [1]. The main types of cell in the epidermis are keratinocytes that retain its function via a multifarious and tightly controlled program of proliferation and terminal differentiation [2]. Skin is frequently exposed to a variety of environmental, chemical, and genotoxic agents that contribute to disease and carcinogenesis [3]. Exposure of skin to ultraviolet (UV) light is a mutual source of skin damage and is the most important cause of skin cancer [4]. Ultraviolet type-B (UVB) is the main component of sunlight that leads to the great damage [5]. Most of the UVB is absorbed by the ozone layer, only $1-5 \%$ reaches our planet. However, UVB is more genotoxic and about 1000fold more capable of causing sunburn than UVA. UVB is less penetrating and mainly acts in the epidermal basal cell layer of the skin [6].
UV exposure, predominantly UVB $(290-320 \mathrm{~nm})$, is the best source of free radicals and related reactive oxygen species (ROS), which play an important role in carcinogenesis by directly damaging cellular macromolecules, including DNA [7-9]. ROS are natural and inseparable part of metabolism; in the skin, they are continually produced in keratinocytes and fibroblasts and are rapidly removed by enzymatic and nonenzymatic antioxidants; this maintains the prooxidant/antioxidant balance, thus resulting in cell and tissue equilibrium [10-12].

Green tea is a dietary plant that contains an important source of polyphenols and next to water, it is the second most commonly consumed beverage in the world after black tea, produced mainly from a single plant species Camellia sinensis [13-15]. Green tea has potential beneficial effects such as solar ultraviolet protection, antimutagenic, antidiabetic, antiinflammatory, anticancer, antioxidant, and immunomodulatory effects. Properties are attributed to the polyphenolic compounds present in green tea, particularly the Catechins, 
which make up 30\% of the dry weight of green tea leaves [16]. A new potential application of epigallocatechin-3-gallate has a role in the prevention or treatment of inflammatory processes and inhibits UV-induced oxidative stress production [17-19]. The aim of the current study was to estimate the effect of green tea in reducing epidermal thickness on mouse's skin exposed to UVB irradiation.

\section{Material and Methods}

2.1. Animal Model. After obtaining the approval from the ethical committee/College of Veterinary Medicine/Sulaimani University, thirty adult albino mice from Mus musculus species, BALB/c strain (15 males and 15 females) were used in this experiment, each of which weighing 25-35 g. The animals were fed with standard pellet diet (Pico Lab) and provided with water ad libitum. Animals were housed in the animal house in Department of Biology, School of Science, Sulaimani University, under a controlled room temperature about $25^{\circ} \mathrm{C}$ and photo-periodicity of 12 hours light/dark system. Animals were assigned into three groups: control group $(n=10)$, which were not exposed to UVB and not treated with green tea; exposure group $(n=10)$ which were exposed to UVB light only; and the remainder group (Treatment, $n=10$ ), which were exposed to UVB and treated with green tea.

2.2. Treatment of Mice with Green Tea. Mice were treated with green tea (Detox, tea pad powder $2.8 \mathrm{~g}$ ). Five tea pads $(14 \mathrm{~g})$ of this powder were weighed in a sensitive balance and dissolved into $10 \mathrm{~mL}$ of warm distilled water in a sterile flask and then shaked well until the powder dissolved completely. Each mouse was treated with $1 \mathrm{~mL}(1.4 \mathrm{mg} /$ day in a single dose) of green tea by oral gavage.

2.3. UVB Irradiation. The source of irradiation was a lamp of $312 \mathrm{~nm}$ wavelength, 15 watts; VILBER-LOURMAT-FRANCE. Mice from both groups (exposure and treatment groups) were exposed to UVB light for 20 minutes/day (4 days/week for 4 consecutive weeks) with a calculated power of $53 \mathrm{mj} / \mathrm{Sec}$. This was done after making a window by shaving the mouse's back skin $(2 \times 5 \mathrm{~cm})$.

2.4. Tissue Biopsy Collection. At the end of the experiments, the animals were anesthetized by using ketamine and xylazine and then euthanized by cervical dislocation. Tissue samples were taken from the dorsal skin. The tissue specimens were fixed at $10 \%$ neutral buffered formalin for at least 24 hours and then routinely processed that were performed in the Histopathology Lab of Consultative Hospital/Sulaimani Governorate. The samples were embedded in paraffin blocks and then cut the sections at a $5 \mu \mathrm{m}$ thickness for Histopathology.

2.5. Histomorphometry. Sections of the dorsal skin were checked out under ordinary light microscope; the measurement and calculation of epidermal thickness from each histological sections were carried out by using an image analyzer (Scope image software 9.0 "H3D" computer systemEngland, digital binocular compound microscope) in the
TABLE 1: The full epidermal thickness measurement for each individual in different groups.

\begin{tabular}{lccc}
\hline & $\begin{array}{c}\text { Control } \\
\text { group }\end{array}$ & $\begin{array}{c}\text { Exposure } \\
\text { group }\end{array}$ & $\begin{array}{c}\text { Treatment } \\
\text { group }\end{array}$ \\
\hline & 6.75 & 70.5 & 20.12 \\
& 6.97 & 74.58 & 20.14 \\
& 6.99 & 89.7 & 21.13 \\
Epidermal & 7.04 & 91.4 & 22.6 \\
thickness $\mu \mathrm{m}$ & 7.05 & 95.6 & 26.1 \\
& 7.43 & 97.2 & 26.23 \\
& 7.45 & 100.9 & 34.2 \\
& 7.59 & 101.9 & 35.4 \\
& 7.8 & 111.3 & 35.5 \\
\hline Mean \pm SEM & 7.95 & 114.7 & 39.3 \\
\hline
\end{tabular}

Histology Department/College of Science/Salahaddin University/Erbil. The full epidermal thickness was checked out by the measuring of epidermal length from the top layer (stratum corneum) to the bottom layer (stratum basale) in five fields with 100 -fold magnifications $(\times 100)$, representing the epidermal thickness, and then the mean was calculated for each sample.

2.6. Statistical Analysis. Epidermal thickness was measured for each case and then mean was calculated and at the end the measurements of each epidermal skin thickness (Mean \pm SEM) of different groups were compared with corresponding epidermal skin thickness of the control group and other groups. The data were analyzed with the SPSS version program 15 (Student's $t$-test (paired) and Pearson's correlation coefficients). A $P$ value of $<0.05$ was considered to be significant.

\section{Result}

3.1. Gross and Microscopic Finding. Physical examination revealed a variation among different groups as detected by manual palpation and gross appearance; in the control group there was a normal skin appearance which was a thin and delicate layer, while in the exposure group variable lesions also were recorded which were started from edema and redness of the exposed area and ended with thickening of the skin and ulceration in some regions at the end of the experiment. However in treated group, the skin almost remained intact with exception of skin thickness which were 1-2 times thinner than the exposed group (Figures 1(a)-1(c)).

Microscopically, the control group had normal skin histology that is comprised of thin epidermis including 23 layers, dermis, and hypodermis; the epidermis of exposed group showed an increase in the number of keratinocytes and epidermal layers (diffuse epidermal hyperplasia) in contrast to the treatment group which developed moderate hyperplasia within the same period of experiment (Figures 2(a)-2(c)) 


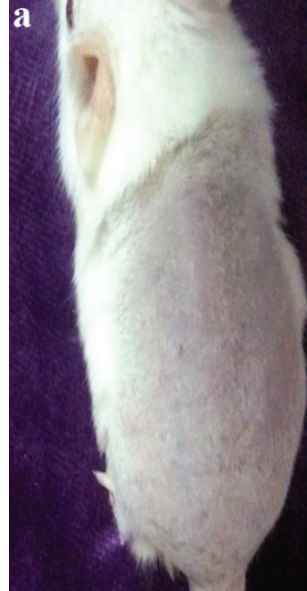

(a)

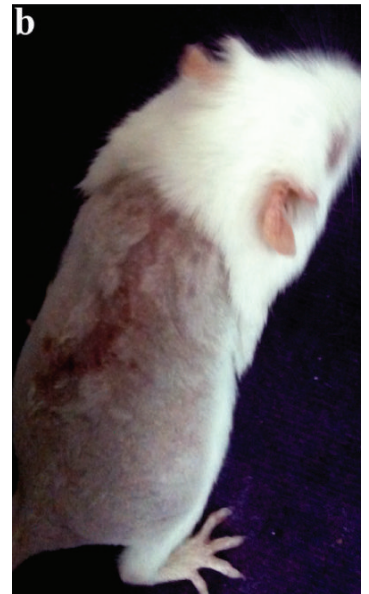

(b)

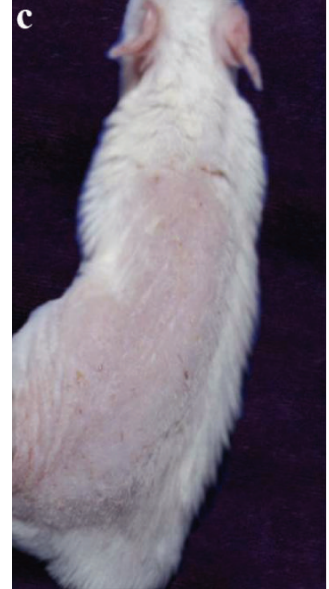

(c)

FIGURE 1: (a) Skin of the control group showed normal thickness; (b) redness and ulceration were found in the skin on exposure group; (c) skin thickness slightly increased in the treated group.

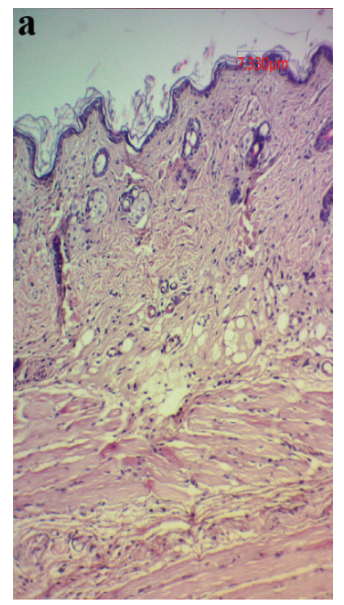

(a)

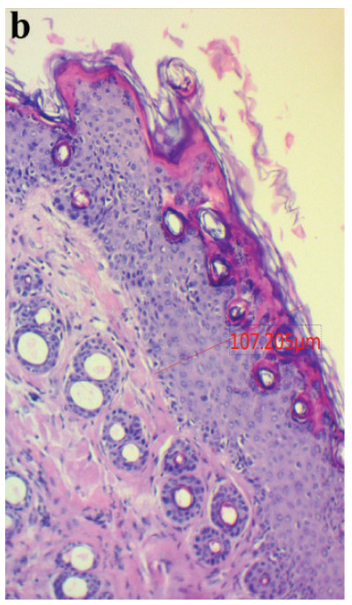

(b)

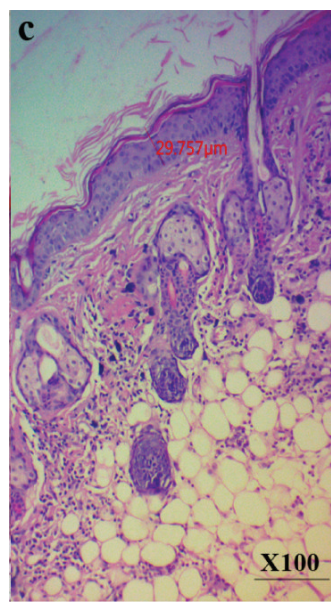

(c)

FIGURE 2: Epidermal thickness in different groups; (a) normal epidermal thickness in the control group; (b) severely increasing epidermal thickness in exposure group; (c) slightly increasing epidermal proliferation in the treated group ( $\times 100, \mathrm{H} \& \mathrm{E}$ stains).

The most obvious lesion observed in the dermis was that there were infiltration of the large number of inflammatory cells including neutrophils, macrophages, and lymphocytes which were diffusely infiltrated in the dermal layer of exposed group while in treating group there was mildly infiltration of inflammatory cells as shown in Figure 3.

3.2. Epidermal Thickness Measurements. Despite those skin lesions which were observed above, epidermal thickness was measured in different cases as shown in Table 1; then the mean of the group was used as a baseline for differentiation among different groups. In the control epidermal thickness ranged from 6.75 to $7.95 \mu \mathrm{m}$ and the mean of the group was equal to $7.302 \pm 0.126$, while epidermal thickness in exposure group indicated an increase which ranged from 70.5 to $114.7 \mu \mathrm{m}$ and the mean was equal to $94.778 \pm 4.471$; this meant that chronic UVB exposure led to an increase in the epidermal thickness 12.979 times more than normal epidermal thickness ( $t=-20.086, P=0.000)$; this finding revealed that there was a highly significant correlation between UVB and increased epidermal thickness according to Pearson correlation coefficient test as shown in Table $2(r=0.921$, $P=0.000)$. In treatment group epidermal thickness was reduced in comparison to the exposure group which ranged from 20.12 to $39.3 \mu \mathrm{m}$ and the mean of the group become $28.072 \pm 2.319$; it meant that green tea 9.135 times reduced the hyperplastic role of UVB in comparison to exposure group $(t=25.640, P=0.000)$ and 3.844 times greater than control group $(t=-9.439, P=0.000, r=0.944, P=0.000)$; also, a positive, strong correlation was found between the exposure group and treatment group $(r=0.897$, $P=0.000)$. 


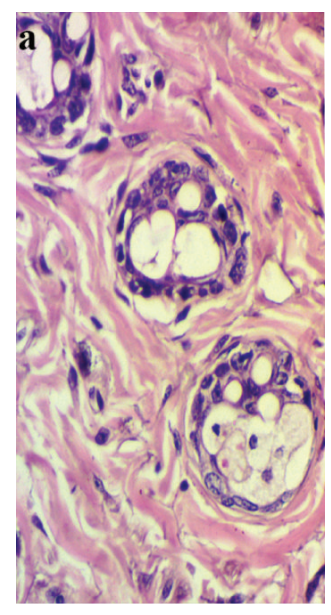

(a)

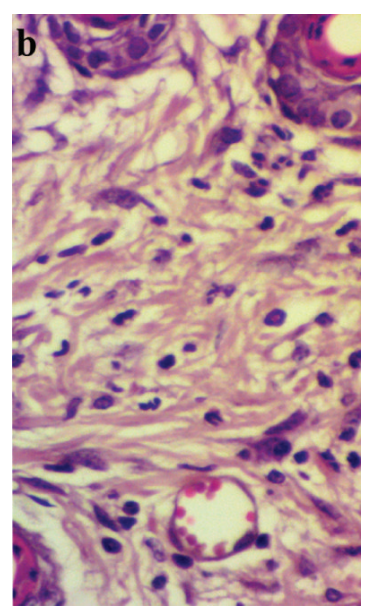

(b)

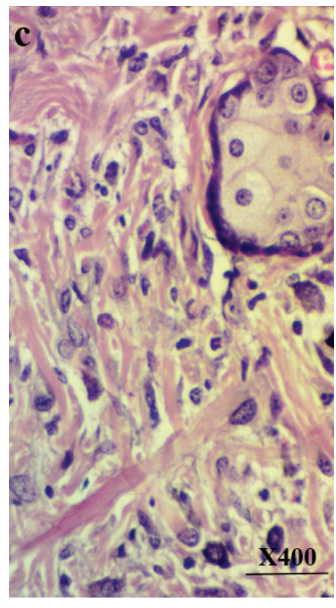

(c)

FIGURE 3: Microscopic views of dermis shows (a): The dermis of control mice, which contains fibroblasts and few macrophages as the normal component of the tissue; (b) mildly infiltration of inflammatory cells in the treatment group; and (c) diffuse infiltration of inflammatory cells in the exposure group $(\times 400, \mathrm{H} \& \mathrm{E}$ stains).

TABle 2: The correlations between different groups by using Pearson's correlation coefficient test.

\begin{tabular}{lcccc}
\hline & & Control group & Exposure group & Treatment group \\
\hline \multirow{2}{*}{ Control group } & Pearson correlation & 1 & $0.921^{* *}$ & $0.944^{* *}$ \\
& Sig. (2-tailed) & & 0.000 & 0.000 \\
\hline \multirow{2}{*}{ Exposure group } & $N$ & 10 & 10 & $0.897^{* *}$ \\
& Pearson correlation & $0.921^{* *}$ & & 0.000 \\
Sig. (2-tailed) & $N$ & 0.000 & 10 & 10 \\
Treatment group & Pearson correlation & 10 & $0.897^{* *}$ & 1 \\
& Sig. (2-tailed) & $0.944^{* *}$ & 0.000 & 10 \\
\hline
\end{tabular}

${ }^{* *}$ Correlation is significant at the 0.01 level (2-tailed).

\section{Discussion}

Ultraviolet radiation is a main environmental factor of skin injury. Its effect on the skin's biology and immune system plays a major role in photo-aging, inflammation, keratinocyte proliferation, epidermal hyperplasia, and carcinogenesis [20, 21].

Our study revealed a significant association between UVB irradiation and increasing epidermal thickness as we observed epidermal thickness in exposure group 12.979 times greater than normal epidermal thickness, this finding agrees with previous reports which documented that UV radiation on the skin induces a variety of responses in the epidermis, including keratinocyte proliferation that leads to epidermal hyperplasia [22-27]. But no previous studies have measured the epidermal thickness induced by UVB in mouse skin.

In this study, UVB irradiation increased infiltration of dermal inflammatory cells in the exposure group due to the effect of chronic UVB irradiation. The inflammatory cells are the potential mediating agents of UV-induced cytokines that leads to epidermal proliferation of keratinocytes and hyperplastic lesion [28-30].

In this current study, we determined that oral administration of green tea was effective in reducing the development of the hyperplasia but not preventing it; this observation is totally in agreement with Jurkiewicz study. In their study, dietary supplementation of antioxidants was found to be less effective than topical application due to the length of time needed to reach optimal concentrations in the skin [31]; also many studies reported that green tea reduced the UV-induced hyperplastic response; it may be due to the antioxidant properties of green tea, that is, increasing various cellular, molecular, and biochemical mechanism, which is playing a role in reducing the skin lesion development [32-34].

Despite the reduction of the hyperplastic effect of UVB from green tea also the current study revealed that oral administration of green tea reduced the infiltration of inflammatory cells; this finding is inconsistent with the previous study, which proved the role of green tea as an antiinflammatory agent [35-37]. 


\section{Conclusion}

Oral administration of green tea was provided photoprotection against UVB induced hyperplasia; therefore, it can be regarded as a natural alternative for photo-protection.

\section{Conflict of Interests}

The authors declare that there is no conflict of interests regarding the publication of this paper.

\section{References}

[1] A. J. Singer and R. A. F. Clark, "Cutaneous wound healing," The New England Journal of Medicine, vol. 341, no. 10, pp. 738-746, 1999.

[2] C. S. Tripp, E. A. G. Blomme, K. S. Chinn, M. M. Hardy, P. LaCelle, and A. P. Pentland, "Epidermal COX-2 induction following ultraviolet irradiation: suggested mechanism for the role of COX-2 inhibition in photoprotection," Journal of Investigative Dermatology, vol. 121, no. 4, pp. 853-861, 2003.

[3] P. Oyetakinwhite, H. Tribout, and E. Baron, "Protective mechanisms of green tea polyphenols in skin," Oxidative Medicine and Cellular Longevity, vol. 2012, Article ID 560682, 8 pages, 2012.

[4] L. H. Kligman, "Photoaging. Manifestations, prevention, and treatment," Dermatologic Clinics, vol. 4, no. 3, pp. 518-528, 1986.

[5] T. Maeda, R. A. Espino, E. G. Chomey et al., "Loss of p21WAF1/ Cip1 in Gadd45-deficient keratinocytes restores DNA repair capacity," Carcinogenesis, vol. 26, no. 10, pp. 1804-1810, 2005.

[6] A. Svobodova, D. Walterova, and J. Vostalova, "Ultraviolet light induced alteration to the skin," Biomedical Papers of the Medical Faculty of the University Palacký, Olomouc, Czechoslovakia, vol. 150, no. 1, pp. 25-38, 2006.

[7] R. J. Black and A. T. Gavin, "Photocarcinogenic risk of narrowband ultraviolet B (TL-01) phototherapy: early follow-up data," British Journal of Dermatology, vol. 154, no. 3, pp. 566-567, 2006.

[8] M. Ichihashi, M. Ueda, A. Budiyanto et al., "UV-induced skin damage," Toxicology, vol. 189, no. 1-2, pp. 21-39, 2003.

[9] P. K. Vayalil, A. Mittal, Y. Hara, C. A. Elmets, and S. K. Katiyar, "Green tea polyphenols prevent ultraviolet light-induced oxidative damage and matrix metalloproteinases expression in mouse skin," Journal of Investigative Dermatology, vol. 122, no. 6, pp. 1480-1487, 2004.

[10] S. K. Katiyar and H. Mukhtar, "Green tea polyphenol (-)-epigallocatechin-3-gallate treatment to mouse skin prevents UVBinduced infiltration of leukocytes, depletion of antigenpresenting cells, and oxidative stress," Journal of Leukocyte Biology, vol. 69, no. 5, pp. 719-726, 2001.

[11] K. Rahman, "Studies on free radicals, antioxidants, and cofactors," Clinical Interventions in Aging, vol. 2, no. 2, pp. 219-236, 2007.

[12] C. S. Sander, H. Chang, S. Salzmann et al., "Photoaging is associated with protein oxidation in human skin In Vivo," Journal of Investigative Dermatology, vol. 118, no. 4, pp. 618-625, 2002.

[13] M. Demeule, J. Michaud-Levesque, B. Annabi et al., "Green tea catechins as novel antitumor and antiangiogenic compounds," Current Medicinal Chemistry-Anti-Cancer Agents, vol. 2, no. 4, pp. 441-463, 2002.

[14] J. Hildesheim and A. J. Fornace Jr., “The dark side of light: the damaging effects of UV rays and the protective efforts of MAP kinase signaling in the epidermis," DNA Repair, vol. 3, no. 6, pp. 567-580, 2004.
[15] K. Rathore and H.-C. R. Wang, "Green tea catechin extract in intervention of chronic breast cell carcinogenesis induced by environmental carcinogens," Molecular Carcinogenesis, vol. 51, no. 3, pp. 280-289, 2012.

[16] H. N. Graham, "Green tea composition, consumption, and polyphenol chemistry," Preventive Medicine, vol. 21, no. 3, pp. 334-350, 1992.

[17] F. Afaq and S. K. Katiyar, "Polyphenols: skin photoprotection and inhibition of photocarcinogenesis," Mini Reviews in Medicinal Chemistry, vol. 11, no. 14, pp. 1200-1215, 2011.

[18] S. K. Katiyar, F. Afaq, A. Perez, and H. Mukhtar, "Green tea polyphenol (-)-epigallocatechin-3-gallate treatment of human skin inhibits ultraviolet radiation-induced oxidative stress," Carcinogenesis, vol. 22, no. 2, pp. 287-294, 2001.

[19] C. Rodríguez-Caso, D. Rodríguez-Agudo, F. Sánchez-Jiménez, and M. A. Medina, "Green tea epigallocatechin-3-gallate is an inhibitor of mammalian histidine decarboxylase," Cellular and Molecular Life Sciences, vol. 60, no. 8, pp. 1760-1763, 2003.

[20] A. Brozyna, B. Zbytek, J. Granese, J. A. Carlson, J. Ross, and A. Slominski, "Mechanism of UV-related carcinogenesis and its contribution to nevi/melanoma," Expert Review of Dermatology, vol. 2, no. 4, pp. 451-469, 2007.

[21] J. D’Orazio, S. Jarrett, A. Amaro-Ortiz, and T. Scott, "UV radiation and the skin," International Journal of Molecular Sciences, vol. 14, no. 6, pp. 12222-12248, 2013.

[22] T. B. El-Abaseri, S. Putta, and L. A. Hansen, "Ultraviolet irradiation induces keratinocyte proliferation and epidermal hyperplasia through the activation of the epidermal growth factor receptor," Carcinogenesis, vol. 27, no. 2, pp. 225-231, 2006.

[23] M. I. El-Sherry, M. A. Zaher, M. M. Salah-El-Din Youssef, and Y. O. El-Amir, "Green tea treatment of ultraviolet-B (UVB) skin carcinogenesis in mice," Cancer Therapy, vol. 5, pp. 301-308, 2007.

[24] S. M. A. Hassan, A. K. Saeed, and A. H. Mehdi, "Histopathologic effect of xylene and ultraviolet type B exposure on mouse skin," International Journal of Current Microbiology and Applied Sciences, vol. 4, no. 5, pp. 997-1004, 2015.

[25] M. S. Iordanov, R. J. Choi, O. P. Ryabinina, T.-H. Dinh, R. K. Bright, and B. E. Magun, "The UV (Ribotoxic) stress response of human keratinocytes involves the unexpected uncoupling of the Ras-extracellular signal-regulated kinase signaling cascade from the activated epidermal growth factor receptor," Molecular and Cellular Biology, vol. 22, no. 15, pp. 5380-5394, 2002.

[26] A. Ouhtit, H. K. Muller, D. W. Davis, S. E. Ullrich, D. McConkey, and H. N. Ananthaswamy, "Temporal events in skin injury and the early adaptive responses in ultraviolet-irradiated mouse skin," The American Journal of Pathology, vol. 156, no. 1, pp. 201207, 2000.

[27] A. Saeed and N. Salmo, "Epidermal growth factor receptor expression in mice skin upon ultraviolet $\mathrm{B}$ exposure-Seborrheic Keratosis as a coincidental and unique finding," Advanced Biomedical Research, vol. 1, article 59, 2012.

[28] R. Agarwal, S. K. Katiyar, S. G. Khan, and H. Mukhtar, "Protection against ultraviolet $\mathrm{B}$ radiation-induced effects in the skin of SKH-1 hairless mice by a polyphenolic fraction isolated from green tea," Photochemistry and Photobiology, vol. 58, no. 5, pp. 695-700, 1993.

[29] T. A. Wilgus, M. S. Ross, M. L. Parrett, and T. M. Oberyszyn, "Topical application of a selective cyclooxygenase inhibitor suppresses UVB mediated cutaneous inflammation," Prostaglandins \& Other Lipid Mediators, vol. 62, no. 4, pp. 367-384, 2000 . 
[30] Y. Zheng, D. M. Danilenko, P. Valdez et al., "Interleukin-22, a TH17 cytokine, mediates IL-23-induced dermal inflammation and acanthosis," Nature, vol. 445, no. 7128, pp. 648-651, 2007.

[31] B. A. Jurkiewicz, The Role of Free Radicals, Iron, and Antioxidants in Ultraviolet Radiation-Induced Skin Damage, The University of Iowa, 1995.

[32] H. Y. Jeon, J. K. Kim, D. B. Seo, S. Y. Cho, and S. J. Lee, "Beneficial effect of dietary epigallocatechin-3-gallate on skin via enhancement of antioxidant capacity in both blood and skin," Skin Pharmacology and Physiology, vol. 23, no. 6, pp. 283-289, 2010.

[33] T. Osawa, M. Namiki, and S. Kawakishi, "Role of dietary antioxidants in protection against oxidative damage," in Antimutagenesis and Anticarcinogenesis Mechanisms II, vol. 52 of Basic Life Sciences, pp. 139-153, Springer, New York, NY, USA, 1990.

[34] B. Zhao, X. Li, R. He, S. Cheng, and X. Wenjuan, "Scavenging effect of extracts of green tea and natural antioxidants on active oxygen radicals," Cell Biophysics, vol. 14, no. 2, pp. 175-185, 1989.

[35] A. E. Chiu, J. L. Chan, D. G. Kern, S. Kohler, W. E. Rehmus, and A. B. Kimball, "Double-blinded, placebo-controlled trial of green tea extracts in the clinical and histologic appearance of photoaging skin," Dermatologic Surgery, vol. 31, supplement 1, pp. 855-860, 2005.

[36] S. K. Katiyar, M. S. Matsui, C. A. Elmets, and H. Mukhtar, "Polyphenolic antioxidant (-)-epigallocatechin-3-gallate from green tea reduces UVB-induced inflammatory responses and infiltration of leukocytes in human skin," Photochemistry and Photobiology, vol. 69, no. 2, pp. 148-153, 1999.

[37] J. A. Nichols and S. K. Katiyar, "Skin photoprotection by natural polyphenols: anti-inflammatory, antioxidant and DNA repair mechanisms," Archives of Dermatological Research, vol. 302, no. 2, pp. 71-83, 2010. 

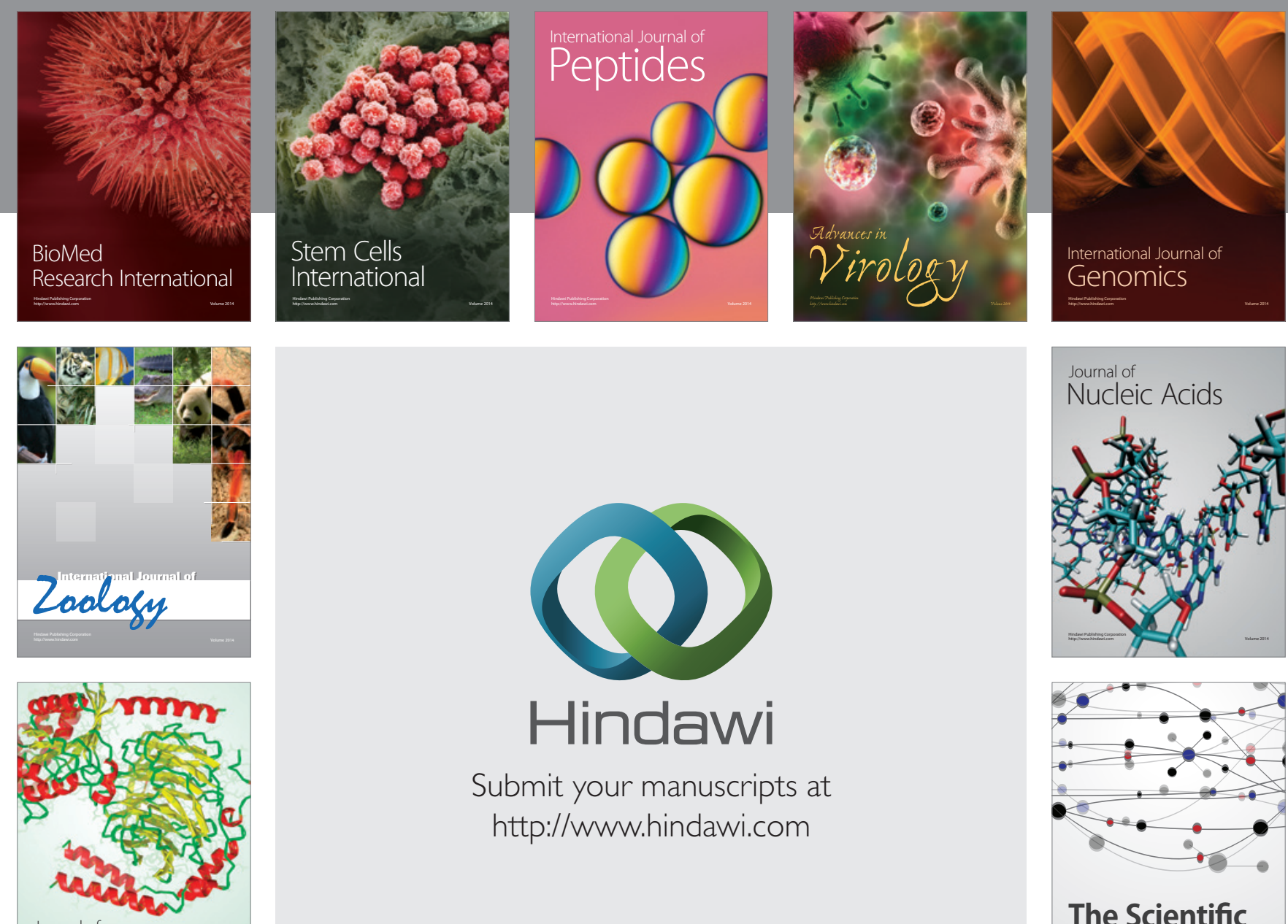

Submit your manuscripts at

http://www.hindawi.com

Journal of
Signal Transduction
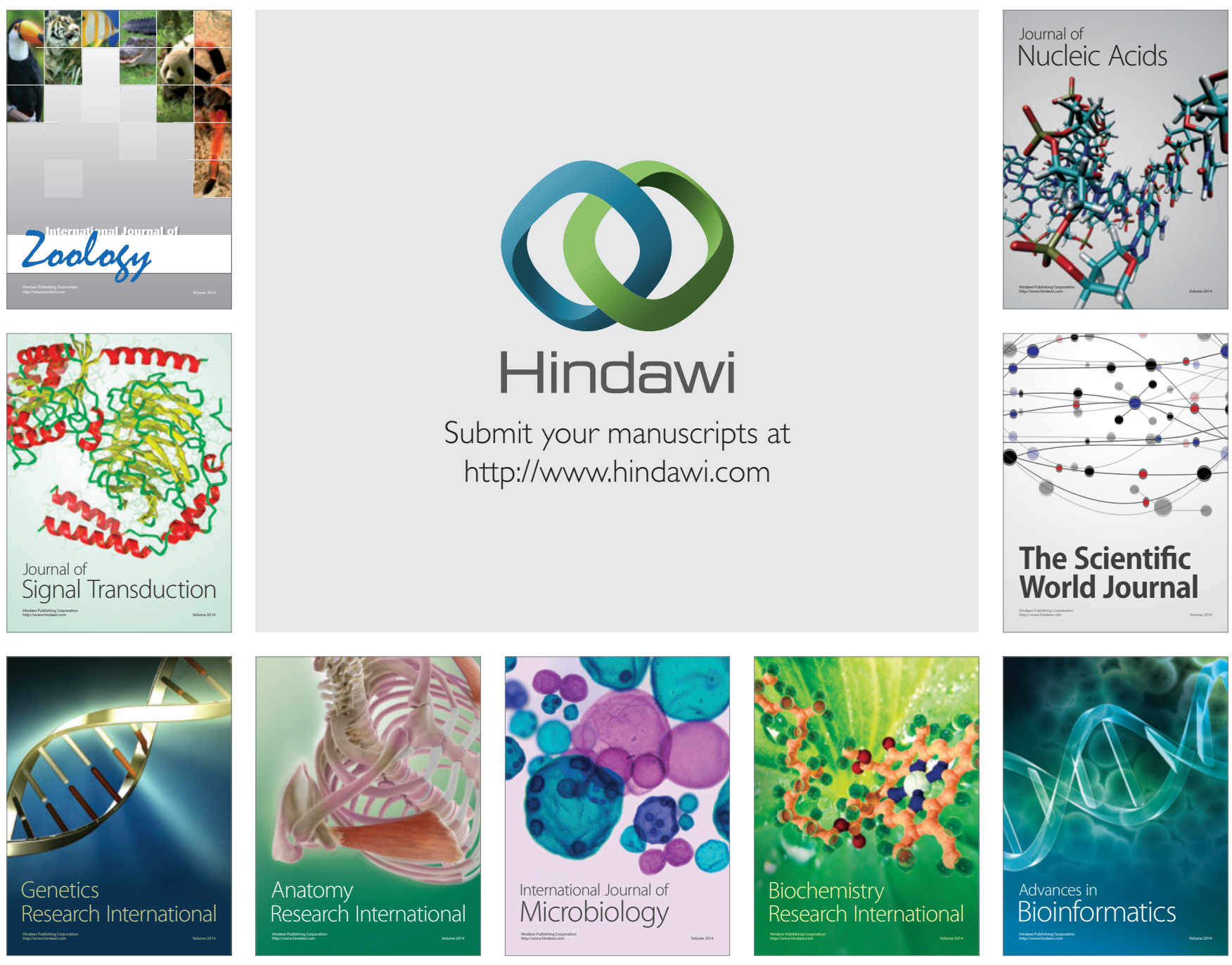

The Scientific World Journal
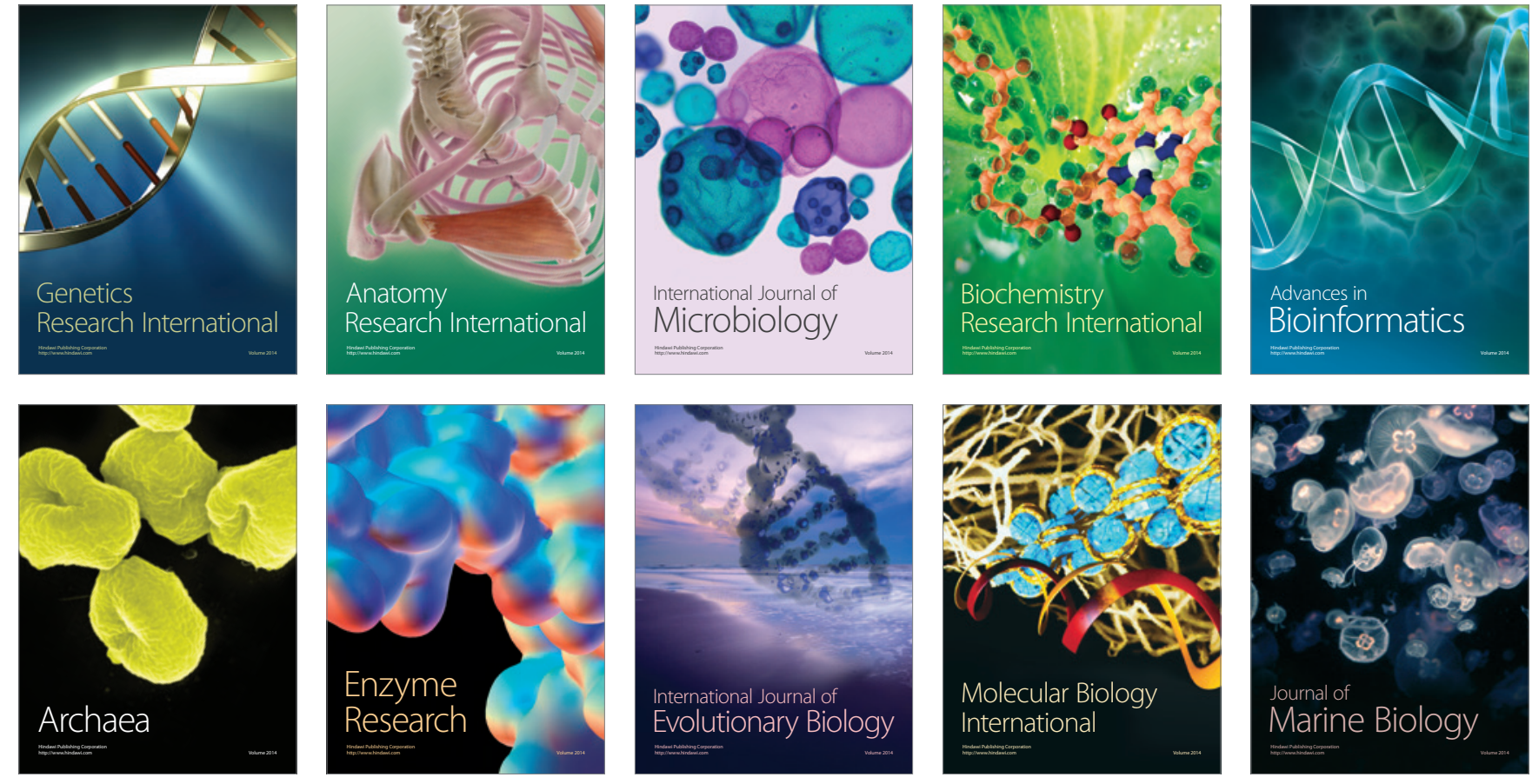